\title{
Surface Active Ionic Liquids Based Coatings as Subaerial Anti-Biofilms for Stone Built Cultural Heritage
}

\author{
Filomena De Leo $^{1}{ }^{\mathbb{D}}$, Alessia Marchetta ${ }^{1}\left(\mathbb{D}\right.$, Gioele Capillo $^{2} \mathbb{D}$, Antonino Germanà ${ }^{2}$, Patrizia Primerano ${ }^{3}$, \\ Sandra Lo Schiavo ${ }^{1, *(\mathbb{D})}$ and Clara Urzì ${ }^{1, *(\mathbb{D})}$
}

1 Department of Chemical, Biological, Pharmaceutical and Environmental Sciences, University of Messina, Viale F. Stagno d'Alcontres, 31, 98166 Messina, Italy; fdeleo@unime.it (F.D.L.); alessia.marchetta@unime.it (A.M.)

2 Department of VeterinarySciences, University of Messina, Polo Universitario SS Annunziata, 98168 Messina, Italy; gioele.capillo@unime.it (G.C.); antonino.germana@unime.it (A.G.)

3 Engineering Department, University of Messina, Contrada di Dio Vill. Sant'Agata, 98166 Messina, Italy; patrizia.primerano@unime.it

* Correspondence: sloschiavo@unime.it (S.L.S.); urzicl@unime.it (C.U.)

check for updates

Citation: De Leo, F.; Marchetta, A.; Capillo, G.; Germanà, A.;

Primerano, P.; Schiavo, S.L.; Urzì, C. Surface Active Ionic Liquids Based Coatings as Subaerial Anti-Biofilms for Stone Built Cultural Heritage.

Coatings 2021, 11, 26. https://

doi.org/10.3390/coatings11010026

Received: 29 November 2020

Accepted: 21 December 2020

Published: 28 December 2020

Publisher's Note: MDPI stays neutral with regard to jurisdictional claims in published maps and institutional affiliations.

Copyright: () 2020 by the authors. Licensee MDPI, Basel, Switzerland. This article is an open access article distributed under the terms and conditions of the Creative Commons Attribution (CC BY) license (https: / / creativecommons.org/ licenses/by/4.0/).

\begin{abstract}
New surface active ionic liquids (SAILs), based on cholinium cations and dodecylbenzenesulfonate as anion, have been synthesized and their potential application as antimicrobial colonization agents on cultural heritage $(\mathrm{CH})$ stone materials investigated. The biocidal activity and antifouling capabilities were, preliminarily, evaluated by a screening on pure Gram (+) and Gram ( - ) bacteria strain cultures, yeasts, hyphomycetes and single-celled algae. Tests on stone materials (marble and tufa) vs. a stabilized community, constituted by a mixture of microbial strains, revealed that some SAILs display both antimicrobial and preventive antibiofilm action against new colonization. Analogous tests have been performed on the cholinium@halide precursors.
\end{abstract}

Keywords: biofilm; cultural heritage; marble; calcareous stone; SAIL coatings

\section{Introduction}

Biocolonization of a stone artifact may occur, (a) as spots due to few or single microorganisms (e.g., meristematic fungi) [1,2], (b) as lichenic crusts [3] or (c) as biological patinas or biofilm due to a composite microbial community [4-6]. It is strongly correlated to the physical (porosity, roughness) and chemical characteristics of the matrix stone as well as to environmental conditions [7]. This implies that each conservation procedure should be specifically customized taking into account the moment of intervention, the constituent material features, but also a number of environmental parameters such as outdoor/indoor, light exposure, humidity, airborne particulates, pollution and so on. Further, it has to be contextualized in a long-term restorative project, which fulfills green conservation criteria such as either nondestructive reversible procedures or both, safety for the environment and for restorers [8-10].

As recently reported [8], there are two possible approaches to cope against biodeteriogens:

- $\quad$ to use biocidal treatments to kill any biodeteriogen organisms, usually organized to form a biofilm on the monument surface;

- $\quad$ to apply designed material-coatings to prevent biofouling on a given surface.

The application of antibiofilm coatings on stone surfaces, especially in outdoor conditions, represents one of the most challenging and pursued means for preventing the colonization process. In this context, nanotechnologies have provided a significant contribution $[8,10]$. Biomimetic approaches have been exploited to obtain micro/nanostructured water-repellant and anti-settling coating surfaces [11-13]. These are configured as alternatives to organic polymers, whose application gave rise to serious drawbacks, becoming, 
over time, examples of negative practice of cultural heritage $(\mathrm{CH})$ conservation methodologies. Furthermore, this approach excludes the use of fluorine additives to gain access to material coatings with reduced surface tension.

Despite remarkable results, the use of nanomaterials and, more generally, of nanotechnologies, is thus far to be considered resolutive. Many issues regarding human health, environmental risks, antimicrobial efficiency, long-term effects and easy application are still questioned [14-18]. For this, as it has been recently pointed out in a recent review [8], QAC-based formulations ( $\mathrm{QAC}=$ quaternary ammonium salts), adopting new sustainable protocols, are still the most widely used products.

In the same review [8], it brought the reader's attention to ionic liquids (ILs), a special class of low melting point salts, which can be engineered by applying Safe by Design concepts to meet green conservation criteria.

The wide interest in ILs $[19,20]$ stems from their ionic nature which, by a proper selection of the cation@anion ion pair, allows a synthetic control of their functions [21-23], including bioactivity [24-27]. Ammonium, phosphonium and imidazolium are the most conventional cations. The anions may be simple halides or more intriguing organic and inorganic species and may act as modulating agents of some physico-chemical properties such as hydrophobicity and viscosity [28]. Il "greenness" was initially mainly associated with its low vapor pressure and recyclability [29]. On the basis of many studies regarding their biodegradability, toxicity and environmental impact, it was revised [30-32]. This led to the so called "ILs of third generation", engineered by applying Safe by Design principles, also based on naturally occurring and more degradable ions, including drugs [33].

Our studies regarding the biocide activity of a series of ammonium ILs vs. microbial strains isolated by deteriorated monuments [34], have shown that the surface active dodecylbenzenesulfonate (DBS) derivative was the most efficient towards the Gram $(+)$ strain Micrococcus luteus and that the overall activity was the result of the synergistic effect operating between cation/anion.

Taking in mind ILs Safe by Design concepts, and in order to explore the potential of DBS-based ILs in conservation of stone materials $[19,29,30]$, we planned a systematic investigation on a series of cholinium@DBS ILs. Choline (also known as 2-hydroxyethyltrimethylammonium chloride or cholinium chloride) is considered an environmentally benign and biodegradable IL, recoverable from natural resources and has been introduced as nutrients within the B-complex vitamins [35,36]. Due to their biological compatibility, cholinium based ILs have been among the most investigated. On the other hand, the DBS surfactant, under the sodium salt linear form is "generally" found to be biodegradable under aerobic conditions and GRAS (generally retained as safe) at low concentrations.

Herein, we report on the synthesis and antibiotic and anti-biofilm activity of a series of novel DBS ILs bearing cholinium species as cations. The latter have been functionalized with alkyl chains of moderate lengths (i.e., at 7 and 12 carbon atoms, respectively), in order to balance toxicity and antimicrobial activity and to evidence the role played by DBS. ILs and their halide precursors were tested against bacteria and fungi by using conventional methods such as minimal inhibitory concentration (MIC), minimal bactericidal concentration (MBC) and antimicogram to assess their antimicrobial activity and concentration of use. Finally, they were applied on tufa and marble probes for a period of 90 days to evidence their antibiofilm activity and preventive effect against new colonization.

\section{Materials and Methods}

\subsection{Preparation}

\subsubsection{Materials}

All the chemicals and solvents employed, unless otherwise stated, were purchased from Sigma-Aldrich and used as supplied. The cholinium halide precursors, N-(2-hydroxyethyl)-N,Ndimethyl-1-heptanaminium bromide (2), N-(2-Hydroxyethyl)-N,N-dimethyl-1- dodecanaminium bromide (3), $\mathrm{N}, \mathrm{N}^{\prime}$-tetramethyl-N, $\mathrm{N}^{\prime}$-(dihydroxyethyl)-1,6-hexanediaminium dibromide (4) and $\mathrm{N}, \mathrm{N}^{\prime}$-tetramethyl-N, $\mathrm{N}^{\prime}$-(dihydroxyethyl)-1,8-octanediaminium diiodide (5) were prepared by 
following established procedure [35,36]. The corresponding cholinium@DBS ILs were labeled by adding the letter " $\mathbf{a}$ " to halide parents, as shown in Figure 1.
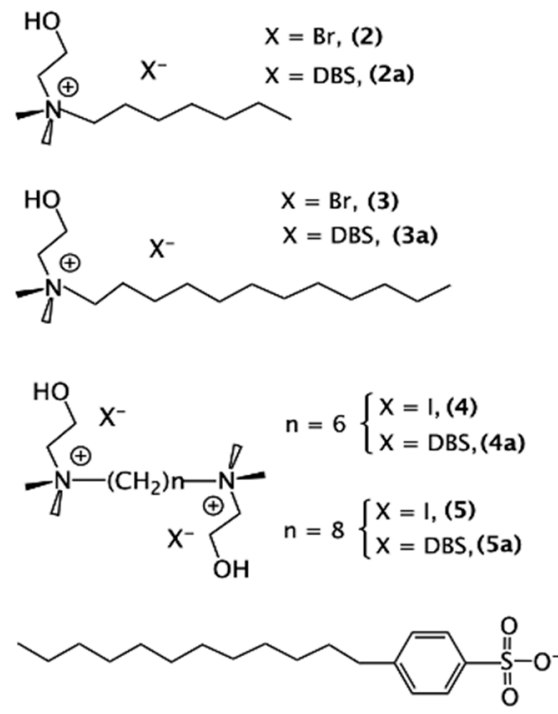

Dodecylbenzensulfonate (DBS)

Figure 1. Schematic representation of cholinium@halides (2-5) and cholinium@DBS ILs (2a-5a).

\subsubsection{Instrumentation}

${ }^{1} \mathrm{H}$ NMR solution spectra were obtained at room temperature on a Bruker AMX R-300 spectrometer operating at $300.13 \mathrm{MHz}$. Chemical shifts $(\delta, \mathrm{ppm})$ were referred to $\mathrm{SiMe}_{4}$. Proton patterns are indicated as s, singlet; $d$, doublet; $t$, triplet; $m$, multiplet and br, broad peak. Infrared transmittance spectra were recorded using a JASCO FT/IR-430 spectrometer (Easton, MD, USA) in the $4000-400 \mathrm{~cm}^{-1}$ scan range, with an instrumental resolution of $4 \mathrm{~cm}^{-1}$ using $\mathrm{KBr}$ / sample mixtures. Elemental analyses were carried out by a Perkin Elmer 2400 CHNS Organic elemental analyzer (Redox S.r.l., Monza, MB, Italy). Differential scanning calorimetry (DSC) measurements were carried out by using a TA Q100 instrument (Vimodrone, Milan, Italy) equipped with a refrigerant cooling system with a heating rate of $10^{\circ} \mathrm{C} \min ^{-1}$ under an anhydrous $\mathrm{N}_{2}$ atmosphere $\left(60 \mathrm{~mL} \mathrm{~min}{ }^{-1}\right)$.

\subsubsection{Syntheses}

N-(2-Hydroxyethyl)-N,N-Dimethyl-1-Heptanaminium Bromide (2)

An acetonitrile solution $(1 \mathrm{~mL})$ containing 2-(dimethylamino)ethanol $(3 \mathrm{~g}, 33.65 \mathrm{mmol})$ and 1-bromoheptane $(6.027 \mathrm{~g}, 33.66 \mathrm{mmol})$ were left under stirring at $50{ }^{\circ} \mathrm{C}$, in an ace pressure tube, for $24 \mathrm{~h}$. After this time, the solution was cooled at room temperature and diethyl ether ( $3 \mathrm{~mL}$ ) added to give 2 as a white solid. The mother liquors were pipetted off and the white solid further washed with diethyl ether, dried in vacuo and kept in dry conditions. Furthermore, $\mathbf{2}$ is a highly hygroscopic solid which left in air becomes a colorless transparent liquid (yields: 90\%). Calculated for $\mathrm{C}_{11} \mathrm{H}_{26} \mathrm{NOBr}$ : $\mathrm{C}, 49.22 \%$; $\mathrm{H}$, 9.76\% and $\mathrm{N}, 5.21 \%$; found: $\mathrm{C}, 49.00 \%$; $\mathrm{H}, 10.00 \%$ and $\mathrm{N}, 5.15 \% .{ }^{1} \mathrm{H} \mathrm{NMR}\left(300 \mathrm{MHz}, \mathrm{CDCl}_{3}\right)$ : $\delta 4.05(\mathrm{~s}, 2 \mathrm{H}), 3.71-3.72(\mathrm{~m}, 2 \mathrm{H}), 3.55-3.50(\mathrm{~m}, 2 \mathrm{H}), 3.32(\mathrm{~s}, 6 \mathrm{H}), 1.72(\mathrm{~s}, 2 \mathrm{H}), 1.33-1.23(\mathrm{~m}, 8 \mathrm{H})$ and $0.84(\mathrm{t}, 3 \mathrm{H})$.

N-(2-Hydroxyethyl)-N,N-Dimethyl-1-Dodecanaminium Bromide (3)

Compound 3 was prepared as a white crystalline solid in $95 \%$ yield, by following the same procedure as for 2. Calculated for $\mathrm{C}_{16} \mathrm{H}_{36} \mathrm{NOBr}$ : C, $56.78 \% ; \mathrm{H}, 10.72 \%$ and $\mathrm{N}, 4.14 \%$; found: C, 56.78\%; H, 10.73\% and N, 4.15\%. ${ }^{1} \mathrm{H} \mathrm{NMR}\left(300 \mathrm{MHz}, \mathrm{CDCl}_{3}\right) \delta 4.04(\mathrm{~s}, 2 \mathrm{H})$, $3.70-3.66(\mathrm{~m}, 2 \mathrm{H}), 3.51-3.46(\mathrm{~m}, 2 \mathrm{H}), 3.30(\mathrm{~s}, 6 \mathrm{H}), 1.67(\mathrm{~s}, 2 \mathrm{H}), 1.28-1.18(\mathrm{~m}, 18 \mathrm{H})$ and 0.81 $(\mathrm{t}, 3 \mathrm{H})$. 
$\mathrm{N}, \mathrm{N}^{\prime}$-Tetramethyl-N,N'-bis(2-Hydroxyethyl)-1,6-Hexanediaminium Dibromide (4)

Compound 4 was prepared as a white crystalline solid in $85 \%$ yield, by following the same procedure as for $\mathbf{2}$ by using a 2:1 2-(dimethylamino) ethanol/1,6-dibromohexane molar ratio. Calculated for $\mathrm{C}_{14} \mathrm{H}_{34} \mathrm{~N}_{2} \mathrm{O}_{2} \mathrm{Br}_{2}$ : C, $39.83 \%$; $\mathrm{H}, 8,11 \%$ and $\mathrm{N}, 6.64 \%$; found: $\mathrm{C}$, $39.86 \% ; \mathrm{H}, 8.13 \%$ and $\mathrm{N}, 6.65 \% .{ }^{1} \mathrm{H}$ NMR $\left(300 \mathrm{MHz}, \mathrm{D}_{2} \mathrm{O}\right) \delta 3.97(\mathrm{~s}, 4 \mathrm{H}), 3.52(\mathrm{~s}, 4 \mathrm{H}), 3.40$ $(\mathrm{m}, 4 \mathrm{H}), 3.10(\mathrm{~s}, 12 \mathrm{H}), 1.74(\mathrm{~s}, 4 \mathrm{H})$ and $1.35(4 \mathrm{H})$.

N,N'-Tetramethyl-N,N'-bis(2-Hydroxyethyl)-1,8-Octanediaminium Diiodide (5)

Compound 5 was prepared as a white crystalline solid in $90 \%$ yield, by following the same procedure as for 4. Calculated for $\mathrm{C}_{16} \mathrm{H}_{38} \mathrm{~N}_{2} \mathrm{O}_{2} \mathrm{I}_{2}: \mathrm{C}, 35.30 \% ; \mathrm{H}, 7.03 \%$ and $\mathrm{N}, 5.1 \%$; found $\mathrm{C}, 35.28 \% ; \mathrm{H}, 7.06 \%$ and $\mathrm{N}, 5.00 \% .{ }^{1} \mathrm{H}$ NMR $\left(300 \mathrm{MHz}, \mathrm{D}_{2} \mathrm{O}\right) \delta 3.97(\mathrm{~s}, 4 \mathrm{H}), 3.50$ $(\mathrm{s}, 4 \mathrm{H}), 3.40-3.37(\mathrm{~m}, 4 \mathrm{H}), 3.11(\mathrm{~s}, 12 \mathrm{H}), 1.74(\mathrm{~s}, 4 \mathrm{H})$ and $1.29-1.31(\mathrm{~m}, 8 \mathrm{H})$.

$\mathrm{N}$-(2-Hydroxyethyl)-N,N-Dimethyl-1-Heptanaminium Bromide Dodecylbenzenesulfonate (2a)

A mixture of $2(2.12 \mathrm{~g}, 7.88 \mathrm{mmol})$ and sodium dodecylbenzenesulfonate (NaDBS) $(2.570 \mathrm{~g}, 7.90 \mathrm{mmol})$ in dichloromethane (DCM) $(20 \mathrm{~mL})$ was left in an ultrasound bath at $50{ }^{\circ} \mathrm{C}$ for $24 \mathrm{~h}$. The resulting white suspension was washed several times with small aliquots of deionized water, until no bromide was detected $\left(\mathrm{AgNO}_{3}\right.$ test). Then, the DCM suspension was taken to dryness to give $\mathbf{2 a}$, as a white waxy solid. Yields $55 \%$. Calculated for $\mathrm{C}_{29} \mathrm{H}_{55} \mathrm{NO}_{4} \mathrm{~S}: \mathrm{C}, 67.77 \%, \mathrm{H}, 10.78 \%$ and $\mathrm{N}, 2.7$; found: $\mathrm{C}, 67.55 \% ; \mathrm{H}, 10.90 \%$ and $\mathrm{N}$, 2.65. ${ }^{1} \mathrm{H}$ NMR (300 MHz, DMSO-d 6 ): $\delta 7.50(\mathrm{~d}, 2 \mathrm{H}), 7.14(\mathrm{~d}, 2 \mathrm{H}), 3.80(\mathrm{~m}, 2 \mathrm{H}), 3.40(\mathrm{~m}, 2 \mathrm{H})$, 3.54-3.49 (m, 2H), $3.08(\mathrm{~s}, 6 \mathrm{H}), 1.70(\mathrm{~s}, \mathrm{br}, 2 \mathrm{H}), 1.429(4 \mathrm{H}), 1,5-0.78(\mathrm{~m}, 29 \mathrm{H})$ and $0.67(\mathrm{t}, 3 \mathrm{H})$.

$\mathrm{N}$-(2-Hydroxyethyl)-N,N-Dimethyl-1-Dodecanaminium Dodecylbenzenesulfonate (3a)

Compound 3a was prepared as a white waxy solid in $50 \%$ yield, by following the same procedure as used for $2 \mathrm{a}$. Calculated for $\mathrm{C}_{34} \mathrm{H}_{65} \mathrm{NO}_{4} \mathrm{~S}: \mathrm{C}, 69.97 \% ; \mathrm{H}, 11.22 \%$ and $\mathrm{N}$, 2.4\%; found: $\mathrm{C}, 69.91 \% ; \mathrm{H}, 11.6 \%$ and $\mathrm{N}, 2.28 \% .{ }^{1} \mathrm{H}$ NMR (300 MHz, DMSO-d $\left.\mathrm{d}_{6}\right) \delta 7.52$ $(\mathrm{d}, 2 \mathrm{H}), 7.13(\mathrm{~d}, 2 \mathrm{H}), 3.79(\mathrm{~m}, 2 \mathrm{H}), 3.39(\mathrm{~m}, 2 \mathrm{H}), 3.53-3.49(\mathrm{~m}, 2 \mathrm{H}), 3.10(\mathrm{~s}, 6 \mathrm{H}), 1.70(\mathrm{~s}, \mathrm{br}$, $2 \mathrm{H}), 1.50-080(\mathrm{~m}, 43 \mathrm{H})$ and $0.60(\mathrm{t}, 3 \mathrm{H})$.

$\mathrm{N}, \mathrm{N}^{\prime}$-Tetramethyl-N,N'-bis(2-Hydroxyethyl)-1,6-Hexanediaminium-

Bisdodecylbenzenesulphonate (4a)

Compound 4a was prepared as a white waxy solid in $38 \%$ yield, by following the same procedure as used for 2a. Calculated for $\mathrm{C}_{50} \mathrm{H}_{92} \mathrm{~N}_{2} \mathrm{O}_{8} \mathrm{~S}_{2}$ : C, $65.74 \% ; \mathrm{H}, 10.15 \%$ and $\mathrm{N}, 3.06 \%$; found: $\mathrm{C}, 65.62 \% ; \mathrm{H}, 10.18 \%$ and $\mathrm{N}, 3.04 \% .{ }^{1} \mathrm{H}$ NMR $\left(300 \mathrm{MHz}, \mathrm{DMSO}-\mathrm{d}_{6}\right) \delta$ $7.51(4,4 \mathrm{H}), 7.10(\mathrm{~d}, 4 \mathrm{H}), \delta 3.97(\mathrm{~s}, 4 \mathrm{H}), 3.52(\mathrm{~s}, 4 \mathrm{H}), 3.40(\mathrm{~m}, 4 \mathrm{H}), 3.10(\mathrm{~s}, 12 \mathrm{H} 4-\mathrm{N}-\mathrm{Me}), 1.74$ $(\mathrm{s}, 4 \mathrm{H}), 1.50-0.78(\mathrm{~m}, 48 \mathrm{H})$ and $0.69(\mathrm{~s}, \mathrm{br}, 6 \mathrm{H})$.

N,N'-Tetramethyl-N,N'-bis(2-Hydroxyethyl)-1,8-OctanediaminiumBisdodecylbenzenesulphonate (5a)

Compound 5a was prepared as a white waxy solid in 35\% yield, by following the same procedure as used for 2a. Calculated for $\mathrm{C}_{52} \mathrm{H}_{96} \mathrm{~N}_{2} \mathrm{O}_{8} \mathrm{~S}_{2}$ : C, $66.33 \% ; \mathrm{H}, 10.20 \%$ and $\mathrm{N}, 2.9 \%$; found: $\mathrm{C}, 65.88 \% ; \mathrm{H}, 11.00 \%$ and $\mathrm{N}, 2.5 \% .{ }^{1} \mathrm{H}$ NMR (300 MHz, DMSO- $\left.\mathrm{d}_{6}\right) \delta 7.50$ $(\mathrm{d}, 4 \mathrm{H}), 7.12(\mathrm{~d}, 4 \mathrm{H}), \delta 3.96(\mathrm{~s}, 4 \mathrm{H}), 3.54(\mathrm{~s}, 4 \mathrm{H}), 3.41(\mathrm{~m}, 4 \mathrm{H}),(\mathrm{s}, 12 \mathrm{H}), 1.74(\mathrm{~s}, 4 \mathrm{H}), 1.55-0.79$ $(\mathrm{m}, 52 \mathrm{H})$ and $0.70(\mathrm{~s}, \mathrm{br}, 6 \mathrm{H})$.

\subsection{Assessment of Antimicrobial and Antifouling Activity}

2.2.1. Microbial Strains

All the strains were isolated from deteriorated stone materials and kept at $-20{ }^{\circ} \mathrm{C}$ in the collection of the Department CHIBIOFARAM, Messina, Italy.

Two bacterial strains Stenotrophomonas maltophilia BC 656 and Micrococcus luteus BC 657, one hyphomycetes Cladosporium sp. MC 853, one black yeast Aureobasidium sp. MC 
875 (Genbank accession numbers KX499457, KX499458, MW284743 and MW284744, respectively), and one unicellular eukaryotic alga (Chlorella sp.) were chosen. Bacterial strains were grown in TSA (Tryptic Casein Soy Agar, Conda Pronadisa) per $24-48 \mathrm{~h}$ at $30{ }^{\circ} \mathrm{C}$ in the dark, while fungi were grown in PDA (Potato Dextrose Agar, Conda Pronadisa) and MEA (Malt Extract Agar, Conda Pronadisa) per $72 \mathrm{~h}$ at $26^{\circ} \mathrm{C}$ in the dark. Algal strain was grown per 10-15 days in liquid and in agarized BG11 medium [37] at room temperature (ranging from $18-22^{\circ} \mathrm{C}$ ) in continuous light (1200 lux).

\subsubsection{Microbial Suspensions}

Microbial cultures were suspended in different solvents depending on the test requirement as specified in the different paragraphs.

The concentration of bacteria was measured with the spectrophotometer Jenway 6400 (Jenway, Staffordshire, UK) $\lambda=540 \mathrm{~nm}$ or by comparing the turbidity of suspension with the 0.5 Mc Farland standard (BioMèrieux, Marcy-l'Etoile, France).

Fungal and algal concentrations were determined by direct counting of spores/cells per $\mathrm{mL}$ in a Thoma-Zeiss counting chamber (Marienfeld, Lauda-Königshofen, Germany).

\subsubsection{Preparation of Stabilized Mixed Culture}

Mixed suspension was prepared by inoculating $50 \mu \mathrm{L}$ of each microbial suspension in 10-fold diluted liquid Bunt and Rovira BRII [38], modified as reported by Urzì et al. [39]. The mixed suspension was then incubated at room temperature and under continuous light conditions and agitation; the amount and variety of different microorganisms were checked every week for one month through decimal dilutions in physiological solution $(0.9 \% \mathrm{NaCl})$ and plating on the Petri dishes containing the abovementioned media by using the micro method (spots of $10 \mu \mathrm{L}$ of each dilution in duplicate were inoculated in plates). For each strain, after incubation, the micro colonies were counted, and the number of microorganisms was determined as $\mathrm{cfu} / \mathrm{mL}$.

\subsubsection{Evaluation of Antimicrobial Activity}

Common techniques to assess antimicrobial activity were used as described below.

For bacteria the minimum inhibitory concentration (MIC) and minimum bactericidal concentration (MBC) [40] were determined with a micro method in 96 sterile well plates (Th. Geyer, Renningen, Germany), while for fungi, due to the need of prolonged time of incubation, the Kirby Bauer disc diffusion test with some modification was used [41-43].

All the compounds (except for $4 \mathbf{a}$ and $5 \mathbf{a}$ prepared at concentrations of $37.5 \mu \mathrm{mol} / \mathrm{mL}$ ) were prepared at concentration of $75 \mu \mathrm{mol} / \mathrm{mL}$ and were diluted in $\mathrm{CH}_{3} \mathrm{OH}$ or in distilled $\mathrm{H}_{2} \mathrm{O}$ depending on either the solubility, type of test or both. Sterilization of the compounds was carried out by filtration through $0.22 \mu \mathrm{m}$ sterile filters (Millex syringe filters, Millipore).

\section{Minimum Inhibitory Concentration (MIC)}

For the determination of MIC, serial dilutions (1:1) of all compounds were prepared in Eppendorf tubes (starting from the initial concentration in sterile distilled water. Each concentration was then distributed in the amount of $150 \mu \mathrm{L}$ in duplicate in the wells.

Each bacterial suspension was inoculated into Müeller-Hinton liquid medium (MH, Conda Pronadisa) twice concentrated $(2 \times)$ and incubated for $2 \mathrm{~h}$ at $30^{\circ} \mathrm{C}$; subsequently, the concentration of the suspension was adjusted to a concentration of $2 \times 10^{5} \mathrm{cell} / \mathrm{mL}$. One hundred and fifty microliters of each suspension were added in each well containing the biocides. Tests were carried out separately for the two strains. Positive controls contained only the bacterial suspension, while negative controls contained only the $1 \times \mathrm{MH}$ medium.

Plates were incubated for $24 \mathrm{~h}$ at $30{ }^{\circ} \mathrm{C}$ and at the end of the incubation time the turbidity in the wells was evaluated by using a microplate reader Bio-Rad Model 2550 EIA spectrophotometer (BioRad, Italy) at $\lambda=492 \mathrm{~nm}$. 
To verify if they act as bactericides or bacteriostatics, minimal bactericide concentration (MBC) was determined by taking $10 \mu \mathrm{L}$ from each well showing no growth and inoculating in duplicate on a plate containing TSA medium. The plates were incubated for $24-48 \mathrm{~h}$ at $30{ }^{\circ} \mathrm{C}$.

After the evaluation of MIC, the wells of the microplates were washed with PBS (phosphate-buffer saline) $0.001 \mathrm{M}$ and, after complete drying of the wells they were stained with $0.5 \% w / v$ Safranin staining solution (Carlo Erba, Milan, Italy) to preliminarily evaluate the antibiofilm activity.

\section{Agar Disc Diffusion Test}

Hyphomycete-Due to the pattern of growth of hyphomycetes, a different protocol was used to test the antifungal activity of compounds against the hyphomycete strain MC 853 Cladosporium sp. as explained below:

Fungal spore suspension was obtained from a fresh culture grown in solid medium PDA (potato dextrose agar, Oxoid) for 7 days at $28^{\circ} \mathrm{C}$, by scraping from the agar surface with a sterile spatula. Conidia were suspended in physiological solution $(0.9 \% \mathrm{NaCl})$ plus $0.001 \%$ Tween 80 to a final concentration of $1 \times 10^{5}$ conidia $/ \mathrm{mL}$. The test was carried out on $120 \mathrm{~mm}$ diameter $(\varnothing)$ Petri dishes containing PDA medium. One $\mathrm{mL}$ of spore suspension was spread onto the agar surface until the suspension was completely absorbed. Paper discs of $6 \mathrm{~mm}$ diameter previously absorbed with $20 \mu \mathrm{L}$ of each chemical compound at the initial concentration, were placed onto the surface at the distance of at least of $24 \mathrm{~mm}$.

Black yeast-A similar protocol described above, was used for the black yeast MC

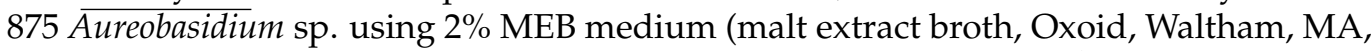
USA) to prepare the suspension with a final concentration of $1.0 \times 10^{6} \mathrm{cell} / \mathrm{mL}$ obtained through direct microscopic count in the Thoma-Zeiss counting chamber; then, with a cotton swab the suspension was homogeneously spread on the surface of the $2 \%$ MEA medium (Malt Extract agar, Oxoid). After complete drying of the surface, paper discs previously absorbed with compounds were put on the agar plates as described above. Petri dishes were incubated for $48-72 \mathrm{~h}$ at $26^{\circ} \mathrm{C}$.

In all cases, negative control discs with only the solvent (methanol or water) for each compound were also set up. After the incubation time, the diameter of the zone of inhibition around the discs was measured and photographed. Experiments were performed in duplicate and average values of the diameters obtained were calculated.

\subsubsection{Evaluation of the Antifouling Efficacy of Coatings on Marble and Tufa Specimens}

In order to evaluate the antifouling efficacy of the newly synthesized compounds, tufa and Carrara marble, very common materials in Italian built $\mathrm{CH}$, were chosen for their different porosity and chemical composition. Probes of $5 \times 5 \times 1.5 \mathrm{~cm}$ dimension were used for the experiments. Surfaces were engraved to obtain 4 sectors $(2.5 \times 2.5 \mathrm{~cm}$ each $)$ and sterilized by autoclaving for $15 \mathrm{~min}$ at $1 \mathrm{~atm}$.

A two-layer coating was prepared by first applying the consolidant NanoEstel as suggested by the producer (CTS S.r.l, Altavilla Vicentina, Italy) diluted 1:5 in sterile distilled water and applied onto the stone probe surfaces with a sterile sponge. Stone probes were kept for 3-4 d at $20^{\circ} \mathrm{C}$ to allow the complete polymerization of the product on the surface. Subsequently, the specimens were sterilized under UV light for $2 \mathrm{~h}$ and then the compounds, 2, 2a, 3 and 3a at concentration of $4.69 \mu \mathrm{mol} / \mathrm{mL}$ and $\mathbf{4 a}$ and $\mathbf{5 a}$ at concentration of $2.34 \mu \mathrm{mol} / \mathrm{mL}$, were applied by using the same technique used for the consolidant. Two different controls, untreated and treated only with consolidant, were prepared.

After drying, contact angle measurements were also performed, to evaluate changes in the hydrophobicity / hydrophilicity of the surfaces.

Untreated and treated marble and tufa probes were therefore inoculated with the mixed stabilized suspension to simulate a natural colonization. Three hundred microliters of the stabilized mixed suspension were inoculated on the surface in duplicate. The specimens were placed in transparent glass containers and incubated for 3 months under light 
( 1200 lux) and at room temperature $\left(\sim 25^{\circ} \mathrm{C}\right)$; a constant humidity was guaranteed by a thick layer of vermiculite, continuously moistened with sterile water, ensuring constant wet conditions. Daily and weekly monitoring were carried out until 90 days through a dissection microscope Leica WILD M10 (Leica Biosystem, Buccinasco, Italy).

At the end of the experiment, microscopical observations were carried out by using the method of adhesive tape sampling [44,45]. In order to evaluate the differences between the most superficial colonization and the one closest to the stone, for each surface two successive samples were taken. The adhesive tape was then placed on a coverslip (Thermo Fisher, Monza, Italy) $24 \times 60 \mathrm{~mm}$ on which a volume of about $30 \mu \mathrm{L}$ of a solution $0.1 \%$ Acridine Orange AO (Thermo Fisher, Monza, Italy) and water was added, in a 1:2 ratio.

The slides were then observed using a confocal microscopy (Zeiss LSM 700, Zeiss, Jena, Germany) equipped with argon and helium-neon lasers for excitation of Green Fluorescent Protein (GFP), A488 green and Fluoresceinisothiocyanate (FITC), A594 red. Images were rapidly acquired to avoid photodegradation. Some images were acquired with bright field backgrounds.

\subsubsection{Contact Angle Measurements.}

These were carried out in a temperature-controlled room kept at $20^{\circ} \mathrm{C}$. Untreated and treated tufa and marble probes were dried and kept in dry conditions for 3 days at the same temperature of the test, in a container with silica gel. A water droplet $(50 \mu \mathrm{L})$ was placed on the surface and a picture of the droplet was taken with a camera. The contact angle was calculated as shown in Figure S1.

\section{Results and Discussions}

\subsection{Syntheses and Characterization of the New Compounds}

Dodecylbenzenesulfonate (DBS) based alkyl-cholinium ILs, 2a-5a (Figure 1), were prepared in two-steps as described in the Materials and Methods Section. In the first one, the alkyl-cholinium halide precursors, $2-5$, were obtained by $\mathrm{N}$-quaternarization of 2 -(dimethylamino)ethanol by using mono- and di-halogenoalkanes, respectively $[35,36]$. More precisely, 1-bromoheptane and 1-bromododecane were used to get 2 and 3, respectively, while the geminal cholinium species, 4 and 5, were obtained by treatment with 1,6dibromohexane and 1,8-diiodooctane, respectively. In the second step, the 2-5 alkyl-cholinium halides were subjected to anion exchange reaction with NaDBS to give the corresponding cholinium@DBSsurfaceactive ionic liquids (SAILs) in moderate (2a and $\mathbf{3 a}$ ) and low yields (4a and $\mathbf{5 a}$ ), respectively. Furthermore, $\mathbf{2 a}-\mathbf{5 a}$ are hygroscopic waxy solids and have to be kept in dry conditions before being analyzed. The synthesis of $\mathbf{4 a}$ and $5 \mathbf{a}$ was not improved because they displayed no significant antimicrobial behavior. ILs constituted by amphiphilic anion and cation, namely, $\mathbf{2} \mathbf{a}$ and $\mathbf{3 a}$, are also referred as catanionic surfactants [46-48]. All novel DBS SAILs have been characterized by elemental analyses, ${ }^{1} \mathrm{H}$ NMR and FT-IR spectroscopy and DSC measurements. The solution NMR spectra afforded a satisfactory integration among the patterns of the aromatic protons of the DBS anion $(7.50-7.00 \mathrm{ppm})$ and the $-\mathrm{CH}_{2}-\mathrm{OH}$ (3.7-3.95 ppm), $-\mathrm{N}-\mathrm{CH}_{2}-(3.4-3.9 \mathrm{ppm})$ and $\mathrm{N}-\mathrm{CH}_{3}$ (3.10-3.05 ppm) proton of cholinium cation, which are significantly lowest field shifted with respect to the other alkyl proton clusters. Consistently, the solid FT-IR spectra displayed, together with the large stretching bands in the range of 3540-2800 $\mathrm{cm}^{-1}$, due to cholinium moiety, additional vibration modes at $1196,1152,1113$ and $1041 \mathrm{~cm}^{-1}$ diagnostic of the sulfonate group.

DSC measurements reveal that the substitution of halide anions by DBS leads to a loss of crystallinity and a general amorphous behavior in the range of temperature considered. In Figure 2, the DSC profiles of $\mathbf{2}$ and $\mathbf{2 a}$, respectively, are reported as a representative example (Lo Schiavo et al., work in progress). The lack of melting phenomena in the thermogram of $2 \mathbf{a}$ is evident, while 2 exhibits a melting point at $112{ }^{\circ} \mathrm{C}$. 


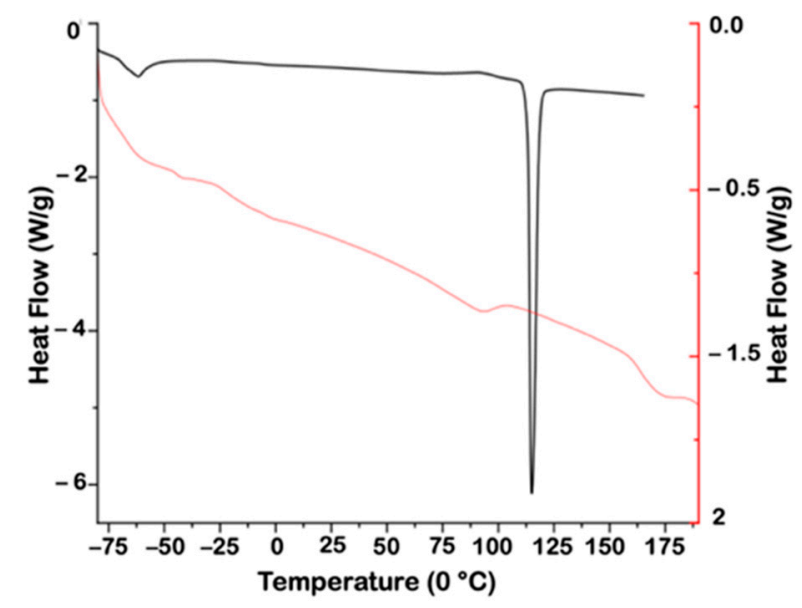

Figure 2. Differential scanning calorimetry (DSC) profiles of $\mathbf{2}$ (black trace) and 2a (red trace), respectively.

\subsection{Determination of Biocidal Activity against Bacterial and Fungal Strains}

The results obtained from MIC determination on the as prepared products were not conclusive, due to the evident opalescence exhibited by $\mathbf{2 a}, \mathbf{3}$ and $\mathbf{3 a}$ solutions before incubation. For this reason, the results were referred to the determination of the Minimum Bactericidal Concentration (MBC) as summarized in Table 1.

Table 1. Result of MBC determination for the Gram+ and Gram- strains.

\begin{tabular}{ccc}
\hline \multirow{2}{*}{ Compounds } & \multicolumn{3}{c}{ MBC $(\mu \mathrm{mol} / \mathrm{mL})$} \\
& Gram (+) BC657 & Gram (-) BC656 \\
\hline $\mathbf{2}$ & 18.75 & 18.75 \\
$\mathbf{2 a}$ & 2.34 & 0 \\
$\mathbf{3}$ & 4.7 & 2.4 \\
$\mathbf{3 a}$ & 0.6 & 9.4 \\
$\mathbf{4}$ & 0 & 0 \\
$\mathbf{4 a}$ & 2.35 & 0 \\
$\mathbf{5}$ & 0 & 0 \\
$\mathbf{5 a}$ & 0.15 & 0 \\
\hline
\end{tabular}

The MBC data evidenced that almost all compounds, with the exception of 4 and 5, exhibited bactericidal activity vs. Gram (+) and only 2, 3 and 3a were effective vs. Gram (-). In general, the sensitivity of Gram (+) and Gram (-) strains were observed at different concentrations, except for 2 that was effective for both strains only at the highest concentrations tested.

As it concerns the biocidal activity vs. fungal strains, it was observed that, already after four days of incubation, the yeast strain Aureobasidium sp. was more susceptible to most of them than the hyphomycete Cladosporium sp. 4 and 5 showed no activity against both fungi. Compound $\mathbf{3}$ and, to a lesser extent, compound $\mathbf{3 a}$, respectively, showed good or discrete fungicidal activity against both fungal strains as shown in Table 2 and in Figures S2 and S3. 
Table 2. Result of anti-micograms against the fungal strains (MC875 and MC853).

\begin{tabular}{ccc}
\hline \multirow{2}{*}{ Compounds } & \multicolumn{2}{c}{ Diameter of Inhibition (mm) } \\
& MC875 & MC853 \\
\hline $\mathbf{2}$ & 13.5 & 0 \\
$\mathbf{2 a}$ & 10.5 & 0 \\
$\mathbf{3}$ & 40 & 27.5 \\
$\mathbf{3 a}$ & 27.5 & 12 \\
$\mathbf{4}$ & 0 & 0 \\
$\mathbf{4 a}$ & 7.5 & 0 \\
$\mathbf{5}$ & 0 & 0 \\
$\mathbf{5 a}$ & 13 & 0 \\
\hline
\end{tabular}

A more detailed analysis of MBC and anti-micogram findings (Tables 1 and 2, respectively) indicates that the most active products, both vs. Gram (+), Gram (-) and fungal strains, are 3 and 3a. To the opposite site, there are the species 4 and 5, which are almost inactive. It is well documented that the antimicrobial activity of QACs is related to their lipophilic features, with the cation playing the main role. In this light, the results obtained are not surprising in that, differently from 4 and 5 , compounds 3 and $3 a$, are featured by the most amphiphilic ion/s (see Figure 1). Interestingly $\mathbf{5 a}$, whose surfactant properties can be ascribed only to the DBS anion, displayed the lowest MBC value $(0.15 \mu \mathrm{m} / \mathrm{L}) \mathrm{vs}$. the Gram (+) strain. Considering the lack of activity of the iodide parent, 5 , it is deduced thatthe DBS anion concurs significantly with the antimicrobial activity of cholinium@DBS vs. Gram (+). Accordingly, 2a-4a all displayed low MBC values. These data corroborate the results obtained from our previous studies regarding a QA-ammonium ILs series [34].

The amphiphilicity of the cation plays a main role vs. Gram (-) in that 3, featuring bromide as anion, displayed the lowest MBC $(2.34 \mu \mathrm{mL})$. It was also the most performant vs. the fungal strains investigated.

\subsection{Effectiveness of Products on Marble and Tufa Specimens}

To test the antimicrobial capabilities of these compounds as coatings, two different typologies of stones have been selected, namely, Carrara marble and tufa, differing both in porosity and chemical composition.

In order to ensure an efficient adherence of such ionic species to stone substrates, these were previously treated with a nano-silica suspension, conventionally used for consolidative purposes. To this aim the commercial product NanoEstel was employed. This consists of a basic suspension $(\mathrm{pH}=10)$ of nano-silica $(20 \mathrm{~nm})$ which, once gelled, induces a negative charge to the stone surface as a result of silanol groups $(\mathrm{Si}-\mathrm{O}-\mathrm{H})$ formation [49]. In this way, ionic species may approach the stone silica surface via electrostatic interaction with the cationic moieties. NanoEstel was preferred to TEOS (tetraethyl orthosilicate) because it is less penetrating and promotes faster cross-linking processes.

\subsubsection{Contact Angle Measurements}

None of the surfaces increased their hydrophobicity after treatment with NanoEstel and treatment with the various products, as shown by the measurement of the contact angle as shown in Table 3. 
Table 3. Contact angle measurements of the untreated and treated surfaces.

\begin{tabular}{|c|c|c|}
\hline \multirow{2}{*}{ Compounds } & \multicolumn{2}{|c|}{ Contact Angle } \\
\hline & Tufa & Marble \\
\hline Untreated & $84^{\circ}$ & $73^{\circ}$ \\
\hline NanoEstel & $81^{\circ}$ & $72^{\circ}$ \\
\hline 2 & $70^{\circ}$ & $71^{\circ}$ \\
\hline $2 a$ & $76^{\circ}$ & $73^{\circ}$ \\
\hline 3 & $66^{\circ}$ & $76^{\circ}$ \\
\hline $3 a$ & $65^{\circ}$ & $74^{\circ}$ \\
\hline $4 a$ & $63^{\circ}$ & $66^{\circ}$ \\
\hline $5 a$ & $48^{\circ}$ & $57^{\circ}$ \\
\hline
\end{tabular}

All surfaces, in fact, were moderately hydrophilic, both before and after coating procedures. In particular, those treated with $\mathbf{4 a}$ and 5 a resulted more hydrophilic, especially for tufa; the marble surface generally maintained the initial characteristics. The relative increasing trend observed for the coated specimens, mainly for tufa, with respect to untreated and the ones treated with silica, may be explained in terms of reorganization of the cholinium groups on the surface, promoted by the attractive interactions with water molecules [50].

\subsubsection{Compound Activity on Inoculated Specimens with Stabilized Mixed Suspension}

The colonization trend of the mixed suspension inoculated on the probes' surfaces was observed at regular intervals and documented at time 0 , at 30, 60 and 90 days of incubation both macroscopically and under microscope.

\section{Tufa Colonization}

Macroscopic results are summarized in Figure 3.

T0

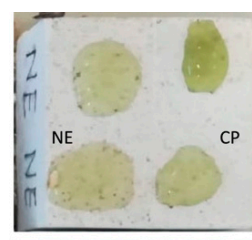

T60

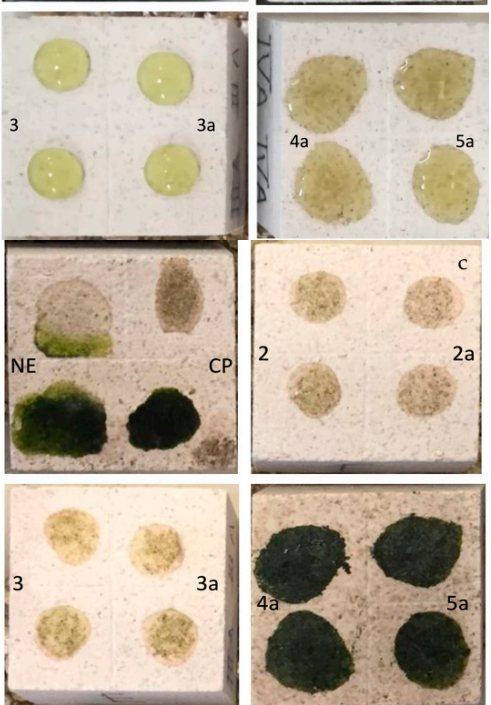

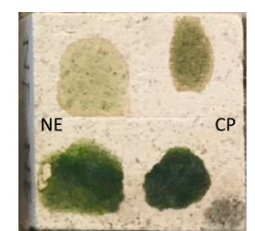
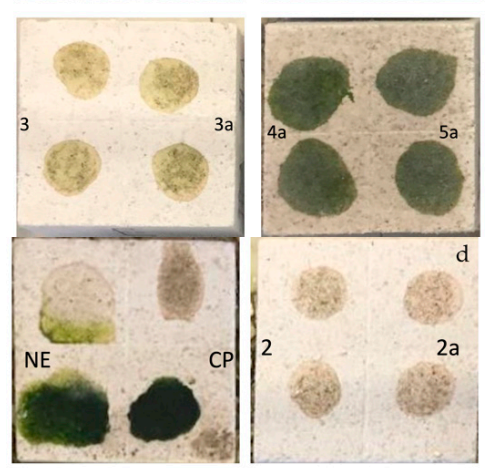

d

$2 a$

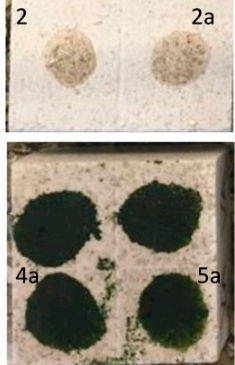

T30

$\mathrm{T} 90$
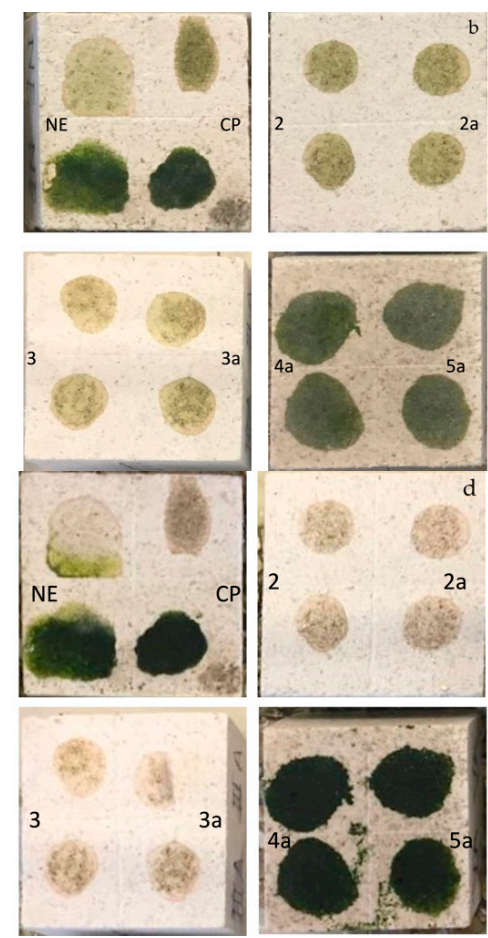

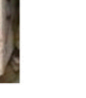

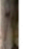

Figure 3. Untreated and treated tufa probes' behavior toward the microbial colonization under laboratory conditions. (a) Immediately after inoculation, T0; (b) after 30 days of incubation under constant illumination, T30; (c) after 60 days of incubation under constant illumination, T60; and (d) at the end of experimentation (90 days of incubation under constant illumination), T90. 
After 30 days of incubation, a good establishment of biofilm in the controls (both untreated and treated with NanoEstel) was observed with some differences in color intensity (Figure 3b). A homogeneous more intense greenish color of the biofilm was observed on the samples coated with $\mathbf{4 a}$ and $\mathbf{5 a}$, while on those treated with 2, 2a, $\mathbf{3}$ and $\mathbf{3 a}$ the biofilm turned a yellow color.

After 60 days of incubation, it was possible to highlight that 3 and $3 a$ caused the drying of the biofilm and algae death (Figure 3c). With the stereomicroscope, only scattered algal residues were observed, while black colonies and fungal filaments were evident, presumably due to Cladosporium sp. (Figure S4).

After 90 days of incubation the degradation process was more evident. The biofilm deposited on the specimens coated with 3 and 3 a results completely dried and the algae disappeared as confirmed by stereomicroscope and CLSM observation (Figures $3 \mathrm{~d}, 4$ and 5).

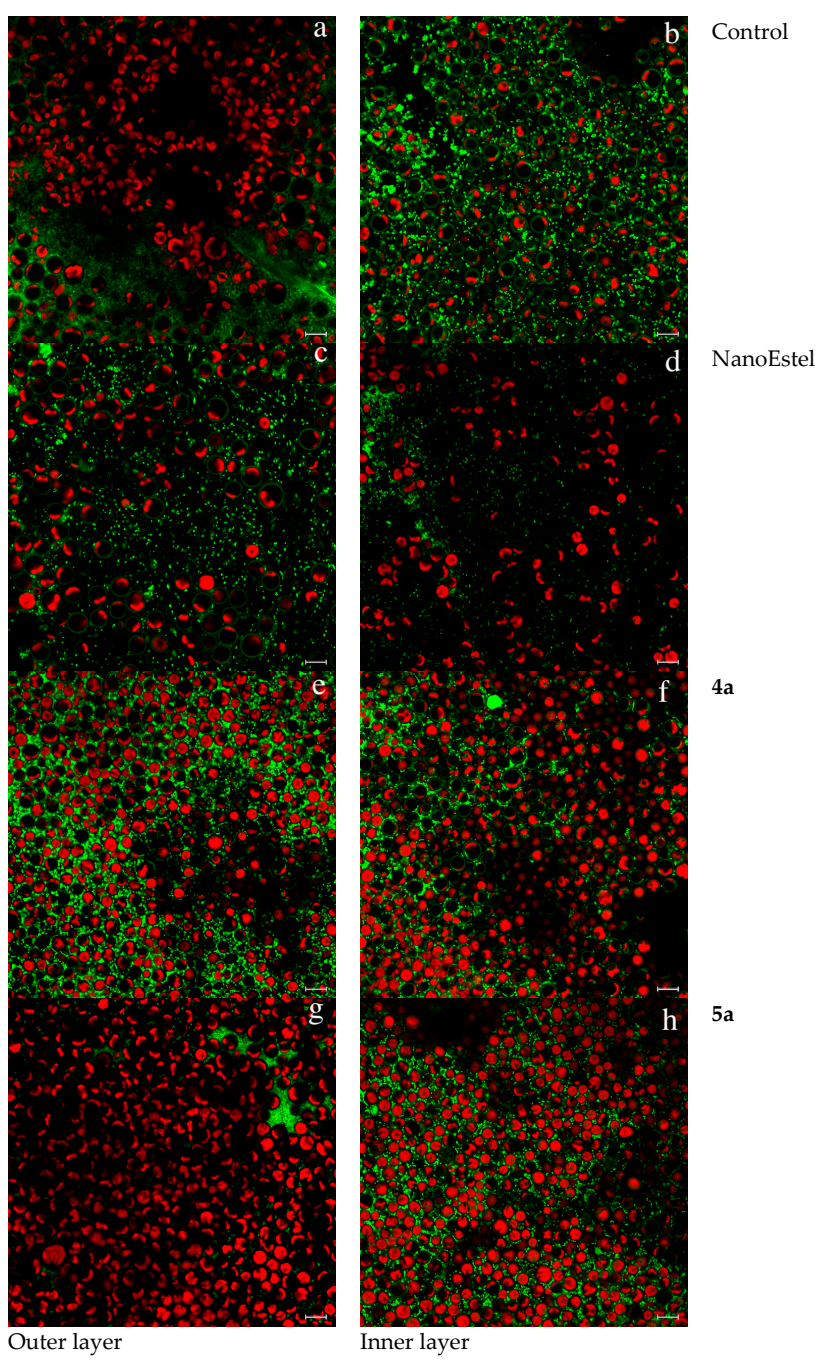

Figure 4. Biofilm behavior on tufa after 90 days of incubation, of untreated samples, samples with only consolidant and with coating treated with compounds $4 \mathbf{a}$ and $5 \mathbf{a}$. Inner and outer layer showed a diverse distribution of microbial members of the biofilm. The different groups are well recognizable being algae colored in red, bacteria in green, while black fungi appear as black areas between the colored cells. Outer and inner layers of biofilm: $(\mathbf{a}, \mathbf{b})$ in the untreated probe it is observed an abundant and healthy biofilm; (c,d) similar behavior on probes treated only with NanoEstel; $(\mathbf{e}, \mathbf{f})$ on areas treated with $\mathbf{4}$ and $(\mathbf{g}, \mathbf{h})$ with $\mathbf{5 a}$ an increase of growth of the biofilm was observed, even more intense than the untreated control. Detailed explanations are given in the text. Bar is $10 \mu \mathrm{m}$. 


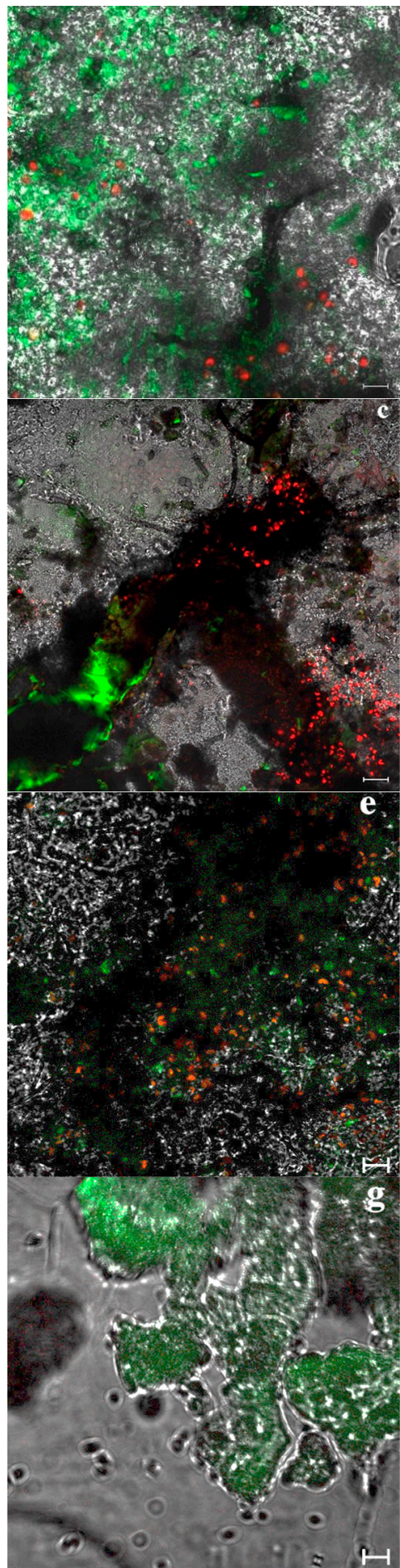

Outer layer

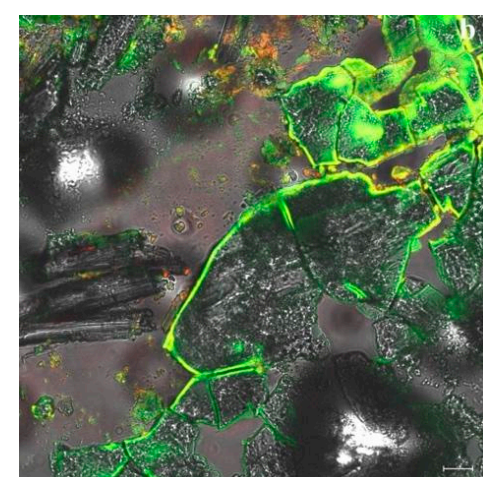

2

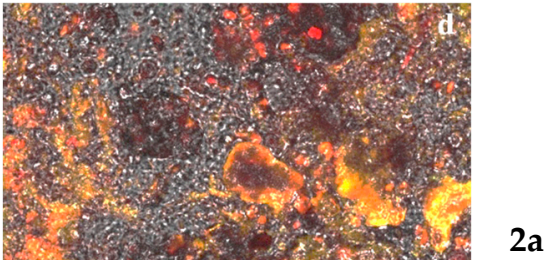

$2 a$

3

$3 a$

Figure 5. Biofilm behavior on tufa after incubation for 90 days, related to the coating treated with compounds 2, 2a, 3 and 3a. Inner and outer layers showed a diverse arrangement of microbial members of the biofilm. The different groups are well recognizable being algae colored in red, bacteria in green, while black fungi appear as black areas between the colored cells.Outer and inner layers of biofilm: $(\mathbf{a}, \mathbf{b})$ in the areas treated with $\mathbf{2} ;(\mathbf{c}, \mathbf{d})$ in the treated with $\mathbf{2 a} ;(\mathbf{e}, \mathbf{f})$ on areas treated with $3 ;(\mathbf{g}, \mathbf{h})$ residues of the coating and very few cells are observed on areas treated with $\mathbf{3 a}$. Detailed explanations are given in the text. Bar is $10 \mu \mathrm{m}$. 
Confocal analyses highlight the biofilm changes as due to the different treatments after 90 days of incubation (Figures 4 and 5). The different groups were well recognizable since algae were colored in red, bacteria in green, while black fungi containing melanin and impossible to show any fluorescence, were recognizable as black areas between the colored cells.

In particular on tufa, while the controls showed a uniform green growth (Figure 3d), the different products showed a different biocidal effect against some of the microorganisms present in the mixed suspension.

The untreated tufa specimens showed the permanence of the various inoculated microorganisms after incubation for 90 days. A different vertical distribution of the microorganisms was observed: in the outer layer algae were more abundant together with black fungi (Figure 4a), while, in the inner layer, bacteria and yeasts and black fungi were evenly distributed, together with few algae (Figure $4 b$ ).

On the surface treated only with silica, algae were equally distributed in the two layers; bacteria were more abundant in the outer layer (Figure 4c) than in the inner one, in this layer black fungi were abundant (Figure 4d).

In the specimens coated with $\mathbf{4 a}$ and $\mathbf{5 a}$, an increase of growth of the biofilm was observed, even more intense than the untreated control. The effective presence of all the microorganism constituent in the mixed suspension was verified by inoculating a small portion of the biofilm in different cultural media. The surfaces treated with compounds 4a and 5a, compared to those of controls, in both cases showed a similar behavior with an intense colonization of algae in both layers, although bacteria and black yeast were still visible (Figure $4 \mathrm{e}-\mathrm{h}$ ).

In the samples treated with 2, 2a, $\mathbf{3}$ and $\mathbf{3 a}$ (Figure 5), in all cases the observation of both layers shows that these products worked quite well, macroscopically showing a very dry biofilm while, under microscope, only traces of the coatings and no or few microbial cells were visible. Stressed algae were evidenced on specimens treated with products 2 and 2a, while fungi were still observed (Figure $5 \mathrm{a}-\mathrm{d}$ ) and confirmed by cultural analysis. Biofilm members were still present in the outer layer of the coating with compound 2 (Figure 5a) with only traces of the coating in the inner layer (Figure 5b); few algae were present in the outer layer treated with compound 2a (Figure 5c), while black fungi were present in the inner layer (Figure 5d). On tufa the coating treated with compounds 3 and 3a showed good antibiofilm activity even against fungi (Figure $5 e-h$ ).

Compound 3a showed a strong activity against algae, bacteria and fungi, as well as the ability to prevent microbial colonization of the porous tufa as clearly shown in Figure 6.
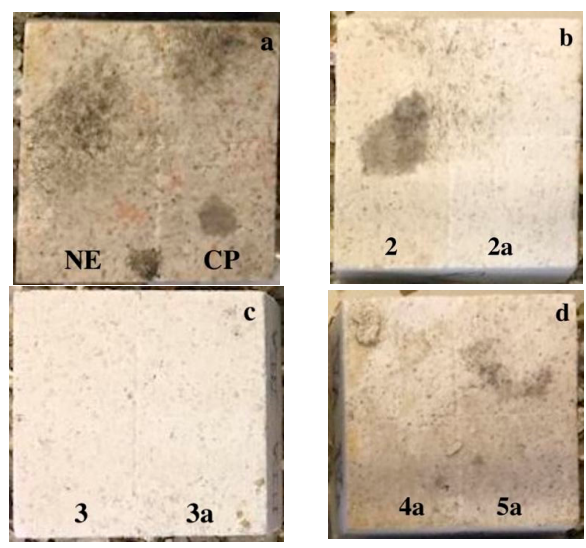

Figure 6. Spontaneous colonization of untreated and treated tufa probes after incubation for 90 days. (a) Untreated (CP) and NanoEstel treated (NE) probes: both show a remarkable fungal growth, visible as black stains; (b) 2 and 2a treated probes: the area treated with $\mathbf{2}$ is colonized by a black fungus, while that one treated with $2 \mathrm{a}$ is rather pristine; (c) $\mathbf{3}$ and $3 \mathbf{a}$ treated probes: no spontaneous colonization is observed; (d) $\mathbf{4} \mathbf{a}$ and $\mathbf{5} \mathbf{a}$ treated probes: spontaneous colonization is observed. 


\section{Performance of Compounds on Marble Specimens}

The macroscopic behavior of untreated and treated marble surfaces toward the microbial biofilm is summarized in Figure 7.
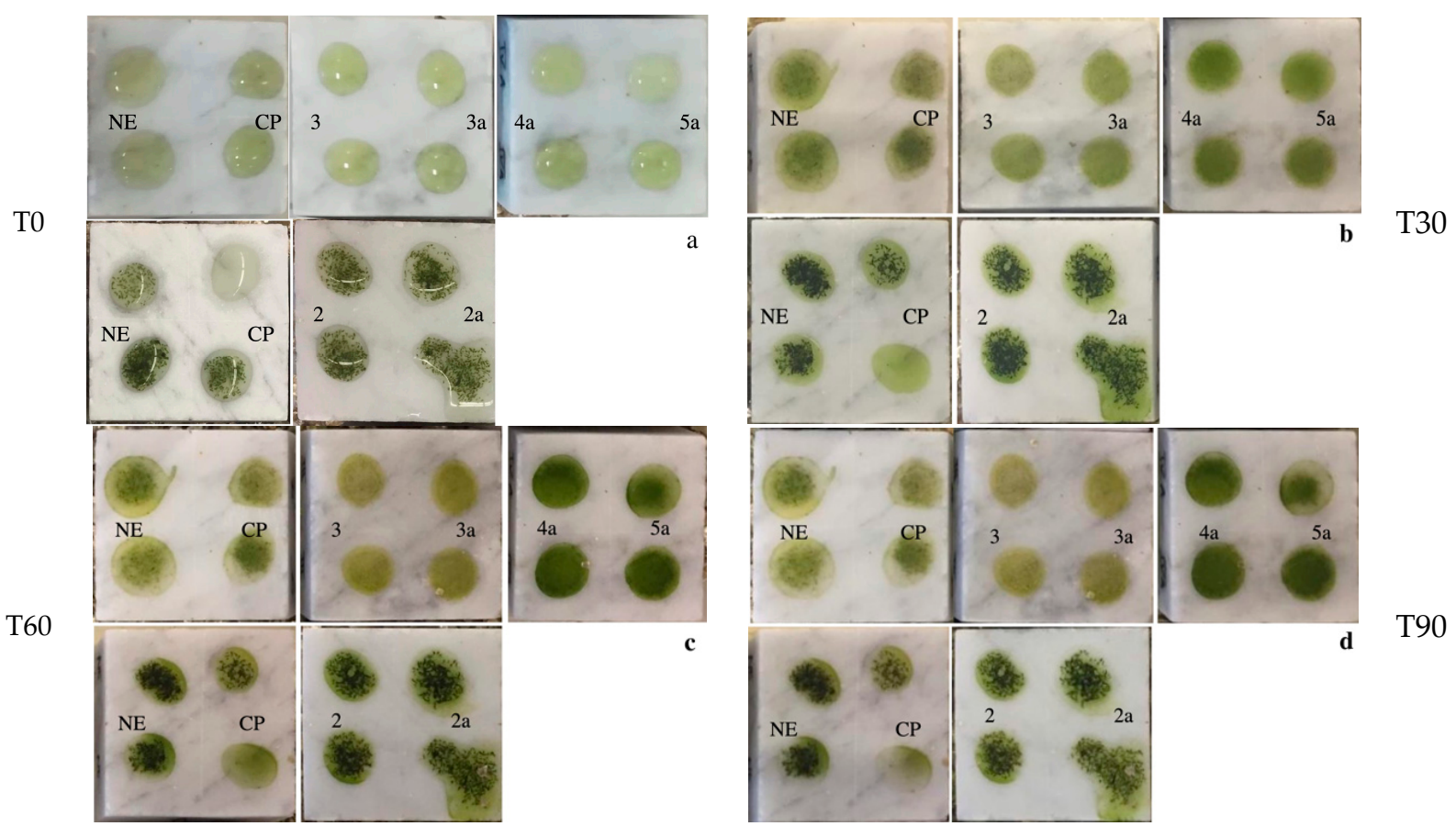

Figure 7. Untreated $(\mathrm{CP})$ and treated marble probes' behavior toward the microbial colonization under laboratory conditions. (a) Immediately after inoculation, T0; (b) after 30 days of incubation under constant illumination, T30; (c) after 60 days of incubation under constant illumination, T60; and (d) at the end of the experiment (90 days of incubation under constant illumination), T90.

On untreated and treated surfaces the inoculated biofilm showed an apparent better resilience than the tufa samples. However, after 90 days of incubation, all coatings showed a very thin biofilm, and the microflora was not as abundant as expected by the color observed macroscopically on marble probes. On the coatings with compounds $\mathbf{3}$ and $\mathbf{3 a}$ the biofilm was very dry, but still greenish.

Regarding the coatings with $\mathbf{4} \mathbf{a}$ and $\mathbf{5} \mathbf{a}$, also on the treated marble, an increase of the biofilm intensity was observed as shown by the dark green color (Figure 8). 

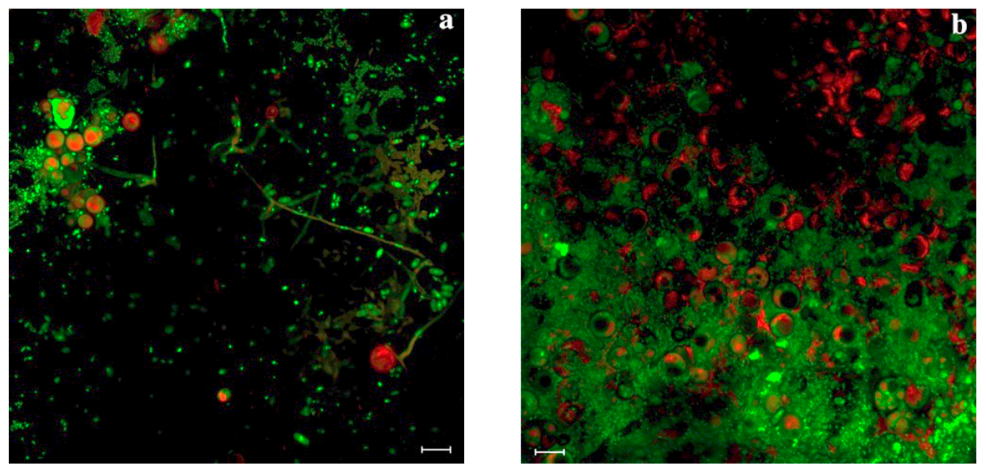

\section{Control}
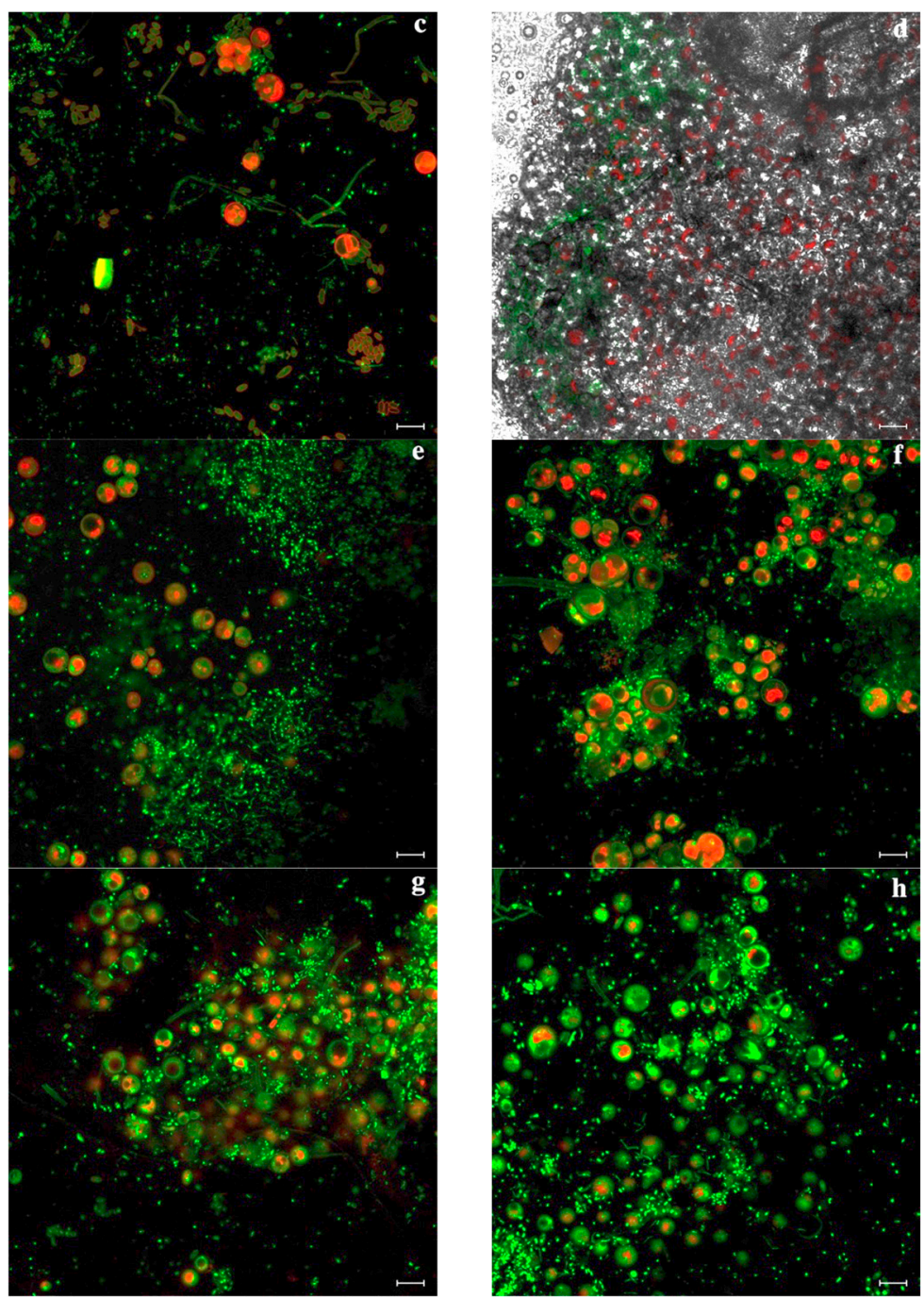

NanoEstel

2

$2 a$

Outer layer

Inner layer

Figure 8. Biofilm behavior on marble probes after incubation for 90 days. Inner and outer layers showed a diverse vertical distribution of microbial members of the biofilm. The different groups are well recognizable being algae colored in red, bacteria in green, while black fungi appear as black areas between the colored cells. Outer and inner layers of biofilm: $(\mathbf{a}, \mathbf{b})$ in the untreated areas; the inner layer harbors a higher amount of microorganisms than the outer layer $(\mathbf{c}, \mathbf{d})$ a similar behavior of the biofilm members is observed in treated area only with NanoEstel; $(\mathbf{e}, \mathbf{f})$ on areas treated with 2 the biofilm is not abundant, algae and bacteria are visible; $(\mathbf{g}, \mathbf{h})$ on treated areas with $\mathbf{2 a}$ it is noticed, besides the reduction of biofilm a certain sufferance of algae with reduction of the red stain intensity. Detailed explanations are given in the text. Bar is $10 \mu \mathrm{m}$. 
In detail, on the control the inner layer harbors a higher amount of microorganisms than the outer one (Figure 8a,b). This is also observed for the NanoEstel coating, on which the inner layer showed a dense fungal colonization (Figure 8c,d). On coatings with 2 (Figure $8 \mathrm{e}, \mathrm{f})$, algae and bacteria were visible in both the inner and outer layers; on coatings 2a (Figure $8 \mathrm{~g}, \mathrm{~h}$ ) besides the reduction of biofilm a certain sufference of algae as seen by the reduction of the red stain intensity; on those with 3, 3a, $\mathbf{4 a}$ and $\mathbf{5 a}$ (Figure 9) fungi were visible in the inner layer. An unexpected result was obtained with the specimen treated with 5a in which, the biofilm was macroscopically dark green (Figure 7d), but only few living algae were observed (Figure 9g).
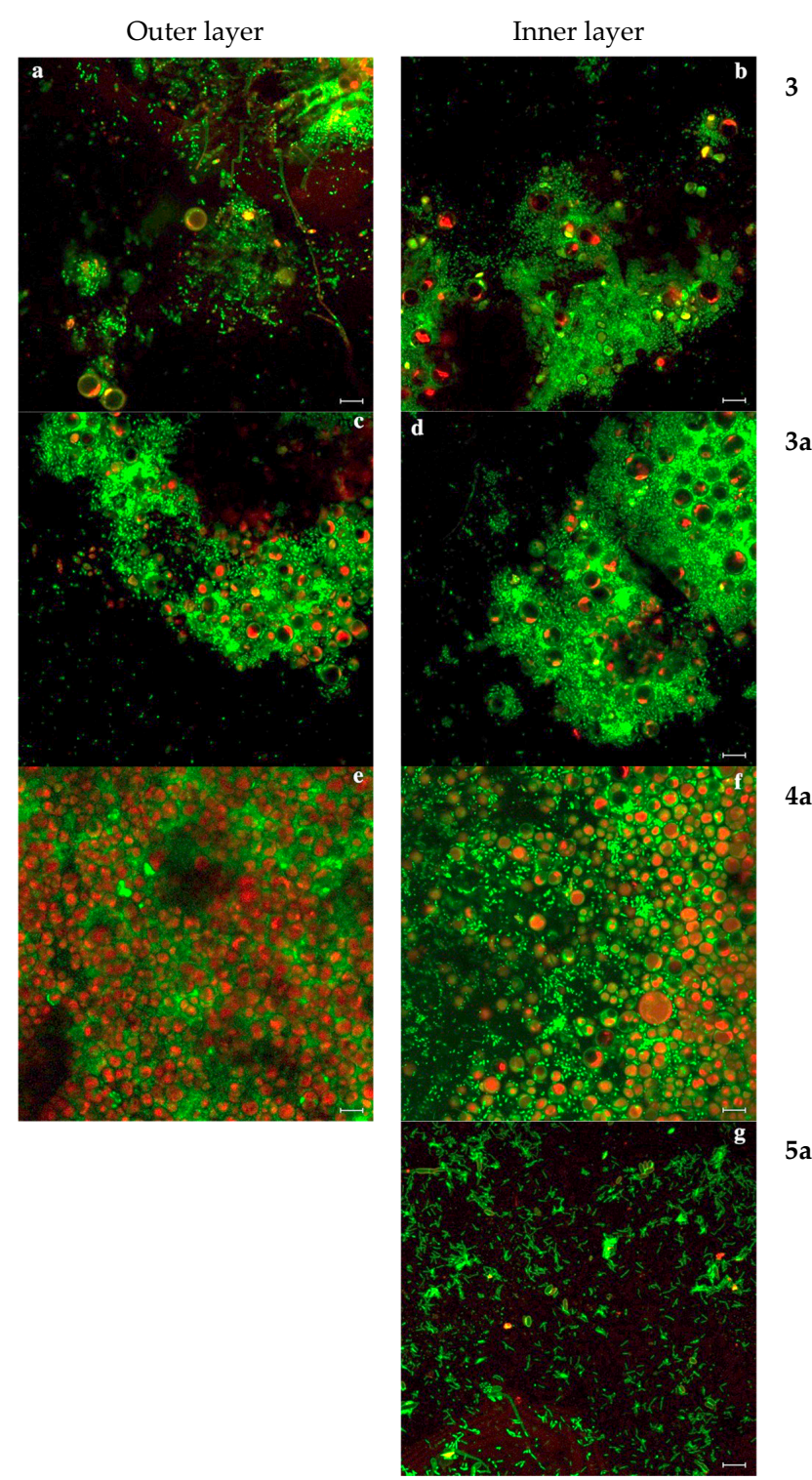

Figure 9. Biofilm behavior on marble probes after incubation for 90 days. Inner and outer layers show a diverse vertical distribution of microbial members of the biofilm according to the treatment. The different groups are well recognizable being algae colored in red, bacteria in green, while black fungi appear as black areas between the colored cells. Outer and inner layers of biofilm: $(\mathbf{a}, \mathbf{b})$ in the samples treated with 3: a shrinkage of biofilm with stressed algae surrounded by bacteria is observed; (c,d) samples treated with 3a: the biofilm is reduced compared to the control, algae are in sufference, as demonstrated by the reduced intensity of red color of algal cells and by the increasing of surrounding bacteria; (e,f) on samples treated with $\mathbf{4 a}$ an healthy biofilm is well evident; (g) inner layer of sample $\mathbf{5 a}$; in this layer only residual cells are visible. Detailed explanations are given in the text. Bar is $10 \mu \mathrm{m}$. 
In the coatings showed in Figure 9a-d treated with $\mathbf{3}$ and $\mathbf{3 a}$, a drastic reduction of the biofilm was observed, the algae were in great stress as demonstrated by the fact that the fluorescence of the chloroplasts was "switched off" compared to that of viable cells and several bacteria surrounded the dying cells ready to use the organic debris of dead cells [51].

On marble treated with coating 4 a (Figure 9e,f) a similar behavior described for tufa was observed, while on the one treated with 5a (Figure 9g), a very little colonization was seen, likely due to the fact that the surface was too dry and the adhesive tape was not able to sample enough biofilm.

\section{Natural Colonization}

Non inoculated tufa and marble (untreated and treated) were used to assess any eventual spontaneous colonization. Table 4 and Figure 6 summarize the results obtained.

Table 4. Behavior of the different coatings applied on tufa and marble probes toward a spontaneous colonization.

\begin{tabular}{|c|c|c|c|c|c|c|}
\hline \multirow{2}{*}{ Coatings } & \multicolumn{2}{|c|}{30 Days } & \multicolumn{2}{|c|}{60 Days } & \multicolumn{2}{|c|}{90 Days } \\
\hline & Tufa & Marble & Tufa & Marble & Tufa & Marble \\
\hline Untreated & + & - & ++ & - & +++ & + \\
\hline NanoEstel & + & - & ++ & - & +++ & + \\
\hline 2 & + & - & ++ & - & +++ & - \\
\hline $2 a$ & + & - & ++ & - & +++ & - \\
\hline 3 & - & - & - & - & - & - \\
\hline $3 a$ & - & - & - & - & - & - \\
\hline $4 a$ & + & - & ++ & - & +++ & + \\
\hline $5 a$ & + & - & ++ & - & +++ & + \\
\hline
\end{tabular}

Non inoculated treated and untreated stone probes, incubated under the same conditions as those inoculated with the mixed suspension, showed a different susceptibility to spontaneous colonization.

As summarized in Table 4, only the surfaces of tufa treated with $\mathbf{3}$ and $\mathbf{3 a}$ did not show any contamination for a time of 90 days, while on marble coatings $\mathbf{2}, \mathbf{2 a}, \mathbf{3}$ and $\mathbf{3 a}$ also did not show any spontaneous colonization. This result demonstrates the effectiveness of these products, especially $\mathbf{3}$ and $\mathbf{3 a}$, in either preventing, slowing down spontaneous colonization or both. The stereo microscope observation showed that the contaminations on the specimens of tufa and marble were very similar to each other. Hyphomycetes have been found with elongated and dark-colored conidia belonging to Cladosporium. A minor contamination was observed on marble specimens compared to that observed on tufa.

All the collected data confirm that the higher the lipophilicity of a species the higher its biocidal activity [19,29-32]. It is noteworthy that, 3a, in other words, the most amphiphilic ILs due to the presence of the DBS anion, also showed a preventive antibiofilm action. In fact, on the tufa specimen coated with $\mathbf{3 a}$, a lifting of the bio-patina was observed (Figure 3). To adduce such a finding to the DBS anions would be pure speculation at the current state of knowledge of these materials. An analogous behavior was not evidenced on marble specimens, suggesting that the higher porosity of tufa, allowed a better penetration of the material coating and higher activity.

On the other hand, all the experiments carried out on coated marble were in agreement with a lower antibiocidal activity for 2, 2a, $\mathbf{3}$ and 3a. Consistently, $\mathbf{4 a}$ and $\mathbf{5 a}$ produced similar effects on tufa and marble.

\section{Conclusions}

The development of new antimicrobial/anti-settlement coatings to control the biodeterioration process on stone $\mathrm{CH}$ sites, especially if exposed outdoors, which matches green conservation requirements still represent a challenge for researchers operating in this field. 
As a part of our general research project aimed at evaluating the potential of surfactant ionic liquids as Safe by Design materials for application in this context, here, we have reported on the results obtained by using cholinium ILs based materials as coatings on marble and tufa lithic substrates. The coating strategy included as a preliminary step the stone surface impregnation with a nano-silica suspension able to create a silica layer which, by electrostatic interaction, allows a good adherence of SA-ionic materials to the surface.

The results obtained, once more confirm the lipophilicity/antimicrobial activity relationship, in that $\mathbf{3}$ and $\mathbf{3 a}$, in other words, the most lipophilic ones, afforded the best performance. Furthermore, 3a, in particular, featuring DBS instead of a halide anion, also experienced a preventive function against new colonization on tufa and marble.

Thinning of the biofilm layer was also observed on treated marble specimens. This suggests that in determining the antimicrobial activity of these compounds, besides the nature of SA-species, also plays a fundamental role to that of the stone substrate.

It is commonly accepted that the mechanism of attack of an ionic surfactant to microbial colonies primarily involves electrostatic/lipophilic interactions between the cation and the wall cell. However, on the basis of studies on SA-ammonium salts/ILs [9,52] and, in particular, on catanionic surfactant as 3a, [46-48] it cannot be excluded that nano-segregation phenomena at coating-air interface may also be operating $[53,54]$.

Further researches are planned to improve the characteristics of these coatings, by using different consolidants, water repellents and, in particular, to evaluate the synergistic effect of the two species 3 and $3 \mathbf{a}$ as suggested by the agar diffusion tests with the Aureobasidium strain.

Supplementary Materials: The following are available online at https:/ / www.mdpi.com/2079-641 2/11/1/26/s1, Figure S1: Determination of the contact angle (from https:/ /www.nanoscience.com/ techniques/tensiometry/). $\theta>90=$ hydrophobic; $\theta<90=$ hydrophilic. Figure S2: Anti-micograms carried out with the strain Aureobasidium sp. MC 875 in 2 Petri dishes of different size: on the left, the Petri dish was $120 \mathrm{~mm}$ diameter, while on the right was $90 \mathrm{~mm}$ diameter. Figure S3: Results of anti-micograms carried out with the strain Cladosporium sp. p MC 853 in 2 Petri dishes of different size: on the left, the Petri dish was $120 \mathrm{~mm}$ diameter, while on the right was $90 \mathrm{~mm}$ diameter. Figure S4. Stereomicroscopic observation of biofilm on tufa treated with (a) $\mathbf{3}$ and (b) 3a, after 60 days of incubation, showing the scattered presence of algae (in green) and fungal spread (in dark). Magnification 630x.

Author Contributions: Conceptualization, S.L.S and C.U.; methodology, S.L.S., C.U., and F.D.L.; formal analysis, F.D.L., A.M., and G.C.; investigation, A.M. and G.C.; resources C.U., F.D.L., and P.P.; data curation, S.L.S., C.U., and F.D.L.; writing-original draft preparation, S.L.S., C.U., and F.D.L.; writing-review and editing, S.L.S., C.U., F.D.L., and A.G.; supervision, S.L.S. and C.U. All authors have read and agreed to the published version of the manuscript.

Funding: This research was partially carried out with the financial contribution of FFABR_2017 and FFABR 2018 (Italian fund for basic research activities).

Data Availability Statement: The data presented in this study are available in the present article and supplementary material.

Acknowledgments: We thank Angelo Nicosia, Dipartimento di Scienze, Università di Catania for DSC measurements and Ivana Morabito for taking part in the experiments for assessment of antimicrobial and antifouling activity.

Conflicts of Interest: The authors declare no conflict of interest. The funders had no role in the design of the study; in the collection, analyses, or interpretation of data; in the writing of the manuscript, or in the decision to publish the results.

\section{References}

1. Sterflinger, K. Fungi: Their role in deterioration of cultural heritage. Fungal Biol. Rev. 2010, 24, 47-55. [CrossRef]

2. De Leo, F.; Antonelli, F.; Pietrini, A.M.; Ricci, S.; Urzì, C. Study of the euendolithic activity of black meristematic fungi isolated from a marble statue in the Quirinale Palace's Gardens in Rome, Italy. Facies 2019, 65, 18. [CrossRef] 
3. Salvadori, O.; Municchia, A.C. The role of fungi and lichens in the biodeterioration of stone monuments. Open Conf. Proc. J. 2016, 7, 39-54. [CrossRef]

4. Saiz-Jimenez, C.; Miller, A.Z.; Martin-Sanchez, P.M.; Hernández-Mariné, M. Uncovering the origin of the black stains in Lascaux Cave in France. Environ. Microbiol. 2012, 14, 3220-3231. [CrossRef] [PubMed]

5. Urzì, C.; De Leo, F.; Bruno, L.; Albertano, P. Microbial diversity in paleolithic caves: A study case on the phototrophic biofilms of the cave of bats (Zuheros, Spain). Microb. Ecol. 2010, 60, 116-129. [CrossRef] [PubMed]

6. Krakova, L.; De Leo, F.; Bruno, L.; Pangallo, D.; Urzì, C. Complex bacterial diversity in the white biofilms of the Catacombs of St. Callixtus in Rome evidenced by different investigation strategies. Environ. Microbiol. 2015, 17, 1738-1752. [CrossRef] [PubMed]

7. Ortega-Calvo, J.J.; Ariño, X.; Hernández-Mariné, M.; Saiz-Jimenez, C. Factors affecting the weathering and colonization of monuments by phototrophic microorganisms. Sci. Total. Environ. 1995, 167, 329-341. [CrossRef]

8. Schiavo, S.L.; De Leo, F.; Urzì, C. Present and future perspectives for biocides and antifouling products for stone-built cultural heritage: Ionic liquids as a challenging alternative. Appl. Sci. 2020, 10, 6568. [CrossRef]

9. Pinna, D. Coping with Biological Growth on Stone Heritage Objects: Methods, Products, Applications, and Perspectives; Apple Academic Press: Oakville, ON, Canada, 2017; ISBN 9781771885324.

10. Artesani, A.; Di Turo, F.; Zucchelli, M.; Traviglia, A. Recent advances in protective coatings for cultural heritage-An overview. Coatings 2020, 10, 217. [CrossRef]

11. Reyes-Estebanez, M.; Ortega-Morales, B.O.; Chan-Bacab, M.; Granados-Echegoyen, C.; Camacho-Chab, J.C.; Pereañez-Sacarias, J.E.; Gaylarde, C.C. Antimicrobial engineered nanoparticles in the built cultural heritage context and their ecotoxicological impact on animals and plants: A brief review. Herit. Sci. 2018, 6, 52. [CrossRef]

12. Zabeo, A.; Giubilato, E.; Badetti, E.; Picone, M.; Ghirardini, A.V.; Hristozov, D.; Brunelli, A.; Marcomini, A. Guiding the development of sustainable nano-enabled products for the conservation of works of art: Proposal for a framework implementing the safe by design concept. Environ. Sci. Pollut. Res. 2019, 26, 26146-26158. [CrossRef]

13. David, M.E.; Ion, R.-M.; Grigorescu, R.M.; Iancu, L.; Andrei, R.E. Nanomaterials used in conservation and restoration of cultural heritage: An up-to-date overview. Materials 2020, 13, 2064. [CrossRef] [PubMed]

14. Manoudis, P.N.; Karapanagiotis, I.; Tsakalof, A.; Zuburtikudis, I.; Kolinkeová, B.; Panayiotou, C. Superhydrophobic films for the protection of outdoor cultural heritage assets. Appl. Phys. A 2009, 97, 351-360. [CrossRef]

15. Pinho, L.; Mosquera, M.J. Titania-silica nanocomposite photocatalysts with application in stone self-cleaning. J. Phys. Chem. C 2011, 115, 22851-22862. [CrossRef]

16. Lejars, M.; Margaillan, A.; Bressy, C. Fouling release coatings: A nontoxic alternative to biocidal antifouling coatings. Chem. Rev. 2012, 112, 4347-4390. [CrossRef] [PubMed]

17. Zarzuela, R.; Luna, M.; Carrascosa, L.A.M.; Mosquera, M.J. Preserving cultural heritage stone: Innovative consolidant, superhydrophobic, self-cleaning, and biocidal products. In Advanced Materials for the Conservation of Stone; Hosseini, M., Karapanagiotis, I., Eds.; Springer Science and Business Media LLC: Cham, Switzerland, 2018; pp. 259-275.

18. Ruffolo, S.A.; La Russa, M.F. Nanostructured coatings for stone protection: An overview. Front. Mater. 2019, 6, 147. [CrossRef]

19. Plechkova, N.V.; Seddon, K.R. Applications of ionic liquids in the chemical industry. Chem. Soc. Rev. 2008, 37, 123-150. [CrossRef]

20. Welton, T. Ionic liquids: A brief history. Biophys. Rev. 2018, 10, 691-706. [CrossRef]

21. Cardiano, P.; Lazzara, G.; Manickam, S.; Mineo, P.G.; Milioto, S.; Schiavo, S.L. POSS-Tetraalkylammonium salts: A new class of ionic liquids. Eur. J. Inorg. Chem. 2012, 2012, 5668-5676. [CrossRef]

22. Castriciano, M.A.; Leone, N.; Cardiano, P.; Manickam, S.; Scolaro, L.M.; Schiavo, S.L. A new supramolecular polyhedral oligomeric silsesquioxanes (POSS)-porphyrin nanohybrid: Synthesis and spectroscopic characterization. J. Mater. Chem. C 2013, 1, 4746-4753. [CrossRef]

23. Cardiano, P.; Fazio, E.; Lazzara, G.; Manickam, S.; Milioto, S.; Neri, F.; Mineo, P.; Piperno, A.; Schiavo, S.L. Highly untangled multiwalled carbon nanotube@polyhedral oligomeric silsesquioxane ionic hybrids: Synthesis, characterization and nonlinear optical properties. Carbon 2015, 86, 325-337. [CrossRef]

24. Pendleton, J.N.; Gilmore, B.F. The antimicrobial potential of ionic liquids: A source of chemical diversity for infection and biofilm control. Int. J. Antimicrob. Agents 2015, 46, 131-139. [CrossRef] [PubMed]

25. Guo, J.; Xu, Q.; Zheng, Z.; Zhou, S.; Mao, H.; Wang, B.; Yan, F. Intrinsically antibacterial poly(ionic liquid) membranes: The synergistic effect of anions. ACS Macro Lett. 2015, 4, 1094-1098. [CrossRef]

26. Egorova, K.S.; Gordeev, E.G.; Ananikov, V.P. Biological activity of ionic liquids and their application in pharmaceutics and medicine. Chem. Rev. 2017, 117, 7132-7189. [CrossRef] [PubMed]

27. Benedetto, A.; Ballone, P. Room-temperature ionic liquids and biomembranes: Setting the stage for applications in pharmacology, biomedicine, and bionanotechnology. Langmuir 2018, 34, 9579-9597. [CrossRef] [PubMed]

28. Cardiano, P.; Mineo, P.; Neri, F.; Schiavo, S.L.; Piraino, P. A new application of ionic liquids: Hydrophobic properties of tetraalkylammonium-based poly(ionic liquid)s. J. Mater. Chem. 2008, 18, 1253-1260. [CrossRef]

29. Plechkova, N.V.; Seddon, K.R. Ionic Liquids:"Designer" Solvents for Green Chemistry: An Introduction; Tundo, P., Perosa, A., Zecchini, F., Eds.; John Wiley \& Sons, Inc: Hoboken, NJ, USA, 2007; pp. 103-130.

30. Petkovic, M.; Seddon, K.R.; Rebelo, L.P.N.; Pereira, C.S. Ionic liquids: A pathway to environmental acceptability. Chem. Soc. Rev. 2011, 40, 1383-1403. [CrossRef] 
31. Santos, J.I.; Gonçalves, A.M.M.; Pereira, J.; Figueiredo, B.F.H.T.; Silva, F.A.E.; Coutinho, J.A.P.; Ventura, S.P.M.; Gonçalves, F. Environmental safety of cholinium-based ionic liquids: Assessing structure-ecotoxicity relationships. Green Chem. 2015, 17, 4657-4668. [CrossRef]

32. Jordan, A.; Gathergood, N. Biodegradation of ionic liquids-A critical review. Chem. Soc. Rev. 2015, 44, 8200-8237. [CrossRef]

33. Ferraz, R.; Branco, L.C.; Prudêncio, C.; Noronha, J.P.; Petrovski, Ž. Ionic liquids as active pharmaceutical ingredients. ChemMedChem 2011, 6, 975-985. [CrossRef]

34. De Leo, F.; Cardiano, P.; De Carlo, G.; Schiavo, S.L.; Urzì, C. Testing the antimicrobial properties of an upcoming "environmentalfriendly" family of ionic liquids. J. Mol. Liq. 2017, 248, 81-85. [CrossRef]

35. Silva, F.A.E.; Siopa, F.; Figueiredo, B.F.; Gonçalves, A.M.M.; Pereira, J.L.; Gonçalves, F.J.M.; Coutinho, J.A.P.; Afonso, C.A.M.; Ventura, S.P. Sustainable design for environment-friendly mono and dicationic cholinium-based ionic liquids. Ecotoxicol. Environ. Saf. 2014, 108, 302-310. [CrossRef] [PubMed]

36. Siopa, F.; Figueiredo, T.; Frade, R.F.M.; Neto, I.; Meirinhos, A.; Reis, C.P.; Sobral, R.G.; Afonso, C.A.M.; Rijo, P. Choline-based ionic liquids: Improvement of antimicrobial activity. Chem. Select 2016, 1, 5909-5916. [CrossRef]

37. Rippka, R.; Stanier, R.Y.; Deruelles, J.; Herdman, M.; Waterbury, J.B. Generic assignments, strain histories and properties of pure cultures of cyanobacteria. J. Gen. Microbiol. 1979, 111, 1-61. [CrossRef]

38. Bunt, J.S.; Rovira, A.D. Microbiological studies of some subantarctic soils. Eur. J. Soil Sci. 1955, 6, 119-128. [CrossRef]

39. Urzì, C.; Brusetti, L.; Salamone, P.; Sorlini, C.; Stackebrandt, E.; Daffonchio, D. Biodiversity of Geodermatophilaceae isolated from altered stones and monuments in the Mediterranean basin. Environ. Microbiol. 2001, 3, 471-479. [CrossRef]

40. Andrews, J.M. Determination of minimum inhibitory concentrations. J. Antimicrob. Chemother. 2001, 48, 5-16. [CrossRef]

41. Bauer, A.W.; Kirby, W.M.; Sherris, J.C.; Turck, M. Antibiotic susceptibility testing by a standardized single disk method. Tech. Bull. Regist. Med Technol. 1966, 36, 493-496. [CrossRef]

42. Commissione Normal. Raccomandazioni Normal: 38/93. Valutazione Sperimentale Dell'efficacia Dei Biocidi; C.N.R.-I.C.R.: Rome, Italy, 1993.

43. NCCLS. Method for Antifungal Disk Diffusion Susceptibility Testing of Yeasts; Approved Guideline; NCCLS: Wayne, PA, USA, 2004; ISBN 1-56238-532-1.

44. Urzì, C.; De Leo, F. Sampling with adhesive tape strips: An easy and rapid method to monitor microbial colonization on monument surfaces. J. Microbiol. Methods 2001, 44, 1-11. [CrossRef]

45. Urzì, C.; Albertano, P. Studying phototrophic and heterotrophic microbial communities on stone monuments. In Methods in Enzymology; Doyle, R.J., Ed.; Academic Press: Cambridge, MA, USA, 2001; Volume 336, pp. 340-355. [CrossRef]

46. Brown, P.; Butts, C.P.; Eastoe, J.; Grillo, I.; James, C.; Khan, A. New catanionic surfactants with ionic liquid properties. J. Colloid Interface Sci. 2013, 395, 185-189. [CrossRef]

47. Reddy, S.T.; Sivaramakrishna, D.; Swamy, M.J. Physicochemical characterization of lauryl glycinate-dodecyl sulfate equimolar complex: A base-triggerable catanionic liposomal system. Colloids Surf. A Physicochem. Eng. Asp. 2017, 516, 139-146. [CrossRef]

48. García, M.T.; Ribosa, I.; Gonzalez, J.J.; Comelles, F. Surface activity, self-aggregation and antimicrobial activity of catanionic mixtures of surface active imidazolium- or pyridinium-based ionic liquids and sodium bis(2-ethylhexyl) sulfosuccionate. J. Mol. Liq. 2020, 303, 112637. [CrossRef]

49. Hendrix, D.; McKeon, J.; Wille, K. Behavior of colloidal nanosilica in an ultrahigh performance concrete environment using dynamic light scattering. Materials 2019, 12, 1976. [CrossRef]

50. Manickam, S.; Cardiano, P.; Mineo, P.; Schiavo, S.L. Star-shaped quaternary alkylammonium polyhedral oligomeric silsesquioxane ionic liquids. Eur. J. Inorg. Chem. 2014, 2014, 2704-2710. [CrossRef]

51. Urzì, C.; De Leo, F.; Krakova, L.; Pangallo, D.; Bruno, L. Effects of biocide treatments on the biofilm community in Domitilla's catacombs in Rome. Sci. Total Environ. 2016, 572, 252-262. [CrossRef]

52. Majumdar, P.; Lee, E.; Gubbins, N.; Christianson, D.A.; Stafslien, S.J.; Daniels, J.; Vanderwal, L.; Bahr, J.; Chisholm, B.J. Combinatorial materials research applied to the development of new surface coatings XIII: An investigation of polysiloxane antimicrobial coatings containing tethered quaternary ammonium salt groups. J. Comb. Chem. 2009, 11, 1115-1127. [CrossRef] [PubMed]

53. Shimizu, K.; Tariq, M.; Freitas, A.A.; Pádua, A.A.H.; Lopes, J.N.C. Self-organization in ionic liquids: From bulk to interfaces and films. J. Braz. Chem. Soc. 2015, 27, 349-362. [CrossRef]

54. Borkowski, A.; Syczewski, M.; Czarnecka-Skwarek, A. Ionic liquids strongly affect the interaction of bacteria with magnesium oxide and silica nanoparticles. RSC Adv. 2019, 9, 28724-28734. [CrossRef] 